
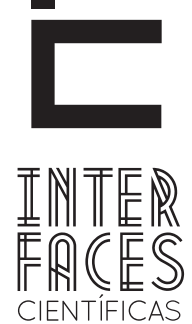

DIREITO

ISSN IMPRESSO 2316-3321

ISSN ELETRÔNICO 2316-381X

\title{
ADMINISTRAÇÃO CONTRATUAL, NOVA CONTRATUALIDADE ADMINISTRATIVA E CONTRATOS DE PARCERIAS: BREVES CONSIDERACÕOES ACERCA DE ALGUNS CONCEITOS QUE INTEGRAM UMA NOVA TERMINOLOGIA TRAZIDA PELA A DOUTRINA ADMINISTRATIVISTA CONTEMPORÂNEA
}

Murilo Ruiz Ferro ${ }^{1}$

André Castro Carvalho²

\section{RESUMO}

Verificadas as polêmicas decorrentes de uma nova terminologia que surge ora para designar institutos potencialmente inéditos ora para manejar outros que já existem, este ensaio procura - por uma linha de raciocínio desenvolvida paralelamente à noção teórica de interesses públicos - encontrar parâmetros conceituais adequados para as expressões doutrinárias "administração contratual", "nova contratualidade administrativa" e "contra- tos de parceria", buscando traçar suas distinções conceituais e também - ainda que de forma sucinta - suas utilizações na prática da Administração Pública brasileira.

\section{PALAVRAS-CHAVE}

Administração Contratual. Nova Contratualidade Administrativa. Contratos de Parceria. Interesses Públicos. 


\section{ABSTRACT}

Verified the controversies arising from a new terminology that appears sometimes to designate institutes potentially manage other unpublished prays that already exist, this work seeks - by a line of reasoning developed in parallel to the theoretical notion of public interests - find suitable parameters for conceptual doctrinal expressions "contractual administration", "new administrative contratuality" and "partnership contracts" seeking to trace their conceptual distinctions and also - albeit briefly - their use in Brazilian Public Administration practice.

\section{KEYWORDS}

Contractual Administration. New Administrative Contratuality. Partnership Contracts. Public Interests.

\section{RESUMEN}

Resumen: Comprobadas las polémicas decurrentes de una nueva terminología que ora aparece para designar institutos potencialmente inéditos y ora para gestionar otros que ya existen. Objeto de este ensayo: - una línea de razonamiento desarrollado en paralelo a la noción teórica de interés público es encontrar los parámetros conceptuales adecuados para las expresiones doctrinales "de gestión de contratos", "nueva contractilidad administrativa" y "contratos de asociación", que tratan de rastrear sus distinciones conceptuales y también - aunque brevemente - y el uso en la práctica, de la administración pública brasileña.

\section{PALABRAS CLAVE}

gestión de contratos; nueva contractilidad administrativa; acuerdos de asociación; los intereses públicos. 


\section{INTRODUÇÃO}

Este trabalho parte basicamente da observação de que um dos problemas correlatos ao processo de evolução do Direito Administrativo - pelo menos, em seu plano teórico - tem sido a própria maturação do seu específico instrumental dogmático, sobretudo a partir do surgimento de uma nova terminologia utilizada tanto para designar institutos potencialmente inéditos quanto para manejar outros que, em verdade, já existem. Neste passo, cabe atentar para o registro de Maria Sylvia Zanella Di Pietro (2008, p. 1):

E isto tudo traz princípios novos, institutos novos e, especialmente, traz nova terminologia; muitas vezes são apenas vocábulos novos que surgem para designar fórmulas antigas que voltam impregnadas de nova ideologia. [...] Ora são institutos velhos que renascem com nova força e sob novo impulso, como a concessão de serviço público; ora são institutos velhos que aparecem com nova roupagem.

E, de fato, nota-se que diversas formulações teóricas começam a ser utilizadas de forma bastante corrente pela dogmática administrativista pós-moderna, isto é, por toda a produção doutrinária de direito administrativo, desenvolvida a partir da segunda metade do século $X X^{3}$. Algumas destas fórmulas, inéditas ou não, podem se apresentar influenciadas por conceitos ideológicos próprios, de modo que, terminologicamente, passem a comportar certa pluralidade de significados. Parece ser o caso das expressões administração contratual, nova contratualidade administrativa e contratos de parceria ${ }^{4}$.

\footnotetext{
3. Registre-se que aqui não será aprofundada a questão da "quebra de paradigmas" ou do "rompimento do pensamento científico moderno, para a construção do pensamento científico pós-moderno, como o faz, de maneira sólida e detalhada, aliás, Diogo de Figueiredo Moreira Neto, em seu "Quatro paradigmas do direito administrativo pós-moderno: legitimidade - finalidade - eficiência - resultados" (MOREIRA NETO, 2008).

4. Maria Sylvia Zanella Di Pietro adverte, com efeito, que a instituição parceria público-privada gerou certa "confusão terminológica". Não por acaso, em sua obra "Parcerias na Administração Pública: concessão, permissão, franquia, terceirização, parceria público-privada e outras formas", dedicou o primeiro tópico do capítulo que trata da "Concessão e Parceria Público-Privada" à “a questão da terminologia” (DI PIETRO, 2008, p. 63-65).
}

Por isso, o objetivo deste ensaio consiste na perquirição de parâmetros conceituais adequados para os termos doutrinários acima mencionados. Afinal, trata-se de expressões que, malgrado estejam entrelaçadas dentro de um mesmo contexto jurídico, não devem ser tecnicamente confundidas umas com as outras.

Metodologicamente, o raciocínio doravante desenvolvido, para que aludidos parâmetros conceituais adequados sejam desvendados, poderia ser desenhado por uma linha cujos pontos, inicial e final, coincidem com a noção - também teórica - de interesses públicos. Essa iniciativa decorre do pressuposto adotado de que o estudo propositivo do Direito Administrativo jamais deve separá-lo daquilo que em essência, presta-se a atingir: a sua finalidade.

Desta feita, para que o presente trabalho cumpra o objetivo ora anunciado, pretende-se, primeiramente, traçar alguns apontamentos sobre interesses públicos e administração contratual. Visa-se, pois, com base nestas duas expressões, construir uma tela de análise que, à luz do chamado direito administrativo pós-moderno, servirá de suporte coerente para a projeção concatenada das ideias posteriores.

Em seguida, foca-se na descrição do fenômeno contratual da administração pública que tem recebido o nome de nova contratualidade administrativa, para demonstrar que os contratos de parceria são, naturalmente, manifestações características da administração contratual.

Em complemento à sequência proposta, parte-se de uma delimitação conceitual do termo contratos de parcerias para demonstrar a aptidão instrumental deste instituto para a consecução dos interesses públicos no contexto do Estado Pós-Moderno.

Caminhando para o final, apresenta-se um resumo do raciocínio que ao longo deste ensaio fora entabulado, sem prejuízo, também, da apresentação de um 
breve apanhado das manifestações doutrinárias que são pertinentes à relação dos contratos de parceria vis-à-vis os interesses públicos.

E por derradeiro, já em sede de considerações finais, intenta-se, com base em todo o exposto, estabelecer as diferenças conceituais das expressões administração contratual, nova contratualidade administrativa e contratos de parcerias, aclarando, possivelmente, os parâmetros conceituais adequados de cada um destes conceitos, bem como buscando demonstrar também - embora de modo geral e perfunctório, é verdade - como esses conceitos vêm sendo utilizados na prática da administração pública brasileira.

\section{INTERESSES PÚBLICOS E ADMINISTRAÇÃO CONTRATUAL: UMA RELAÇÃO INATA AO CHAMADO DIREITO ADMINISTRATIVO PÓS-MODERNO}

O Direito Administrativo é o ramo do Direito Público que, regendo os órgãos, os agentes e as entidades integrantes da Administração Pública, tem a finalidade precípua de proteger o interesse público. No entanto, tratar da noção de interesse público não é tarefa fácil ${ }^{5}$, principalmente quando alocada dentro do contexto da dogmática administrativista pós-moderna, em que esta disciplina sofre - sob influência, obviamente, da pós-modernidade-, um processo de releitura de seus mais caros pressupostos e institutos ${ }^{6}$.

O Estado Pós-Moderno faz que os interesses públicos sejam, no sentido exarado por Alessandro

5. Sobre as dificuldades referentes ao conceito de interesse público, ver o livro "Discricionariedade administrativa na Constituição de 1988" (DI PIETRO, 2007, p.219-222); e o artigo "Interesse público na contratação das entidades da administração centralizada” (DALLARI, 1985 p. 17-26).

6. No Brasil, uma das mais incisivas propostas de releitura teórica do direito administrativo é expressa na obra "Uma teoria do direito administrativo: direitos fundamentais, democracia e constitucionalização" de Gustavo Binenbojm (BINENBOJM, 2006).
Pizzorusso, meras finalidades concretas a serem efetivadas pelos órgãos ou entes públicos, pois, em sociedades pluralistas, como a que vivemos, há tantos interesses públicos quantas forem as comunidades nela coexistentes - e, por consequência, os interesses passam a ser plúrimos (PIZZORUSSO, 1972, p. 72) ${ }^{7}$. Anote-se que esta acepção encontra ressonância no pensamento de Luís Filipe Colaço Antunes ${ }^{8}$ (1989, p. 36), ao lecionar que "não existe um interesse público, mas uma pluralidade de interesses públicos" de forma que "quase podíamos afirmar que nunca o interesse público foi tão privado, em conseqüência dos modelos de concertação social, impostos atualmente pela administração contratual" (Grifos nossos).

A chamada pluralização dos interesses públicos contempla, por decorrência lógica, uma maior complexidade de situações em que o Estado é compelido a agir em favor da coletividade, cada vez mais buscando encontrar novas formas de pactuação - arranjos contratuais, possivelmente, mais adaptáveis às diversas e novas circunstâncias da atuação estatal - com o particular para a consecução da finalidade pública (MARQUES NETO, 2009, p. 79), o que acaba por evidenciar, também, um contexto de aumento da complexidade do fenômeno contratual - ou de sua tendência evolutiva - na Administração Pública.

7. No âmbito doutrinário brasileiro, pensamento semelhante é sustentado por Maria Sylvia Zanella Di Pietro, para quem “[...] a sociedade pluralista faz multiplicarem-se os interesses a serem protegidos; não se fala mais em interesse público de que é titular o Estado, mas de vários interesses públicos, representativos dos vários setores da sociedade civil” (DI PIETRO, 2008, p. 19). 8. Com efeito, é preciso registrar que a brilhante concatenação entre as ideias formuladas pelos juristas Alessandro Pizzorusso e Luís Filipe Colaço Antunes - supra citados - é de autoria de Floriano Peixoto de Azevedo Marques Neto (MARQUES NETO, 2002, p. 152), cuja obra "Regulação estatal e interesses públicos" apresenta uma minuciosa descrição da noção de "interesse público" em seu aspecto histórico-evolutivo. E de seus ensinamentos, sem embargo, embora proveniente de outra passagem, é possível extrair uma ilação que complementa o todo supra transcrito: "Estou convicto que a Administração Pública, hoje, é muito menos uma adjudicadora de direitos previstos na lei e muito mais um árbitro de interesses públicos legítimos colidentes em cada situação concreta [...]”. Concluindo com a seguinte preocupação: “[...] A questão que se põe é como, nesse contexto, conviver ou evitar que estar margem de arbitramento entre esses interesses colidentes seja a porta de entrada dos interesses particularísticos, de prevalência de interesses menores em detrimento dos interesses da coletividade" (MARQUES NETO, 2003, p. 194). 
Essa busca por novas formas de pactuação, também, é oriunda da experiência que a administração pública vai acumulando na celebração de atos e negócios jurídicos para/com o administrado, melhorando o processo de gestão pública.

0 efeito do learning by doing passa a ser uma constante nesses novos desenhos institucionais, experimentados e aprimorados ao longo do tempo pelas diversas administrações públicas. E nesse contexto, nunca o fator experiência (o chamado track record utilizado no mundo empresarial) do setor privado fora tão prestigiado pelo setor público, justamente a fim de apropriar as novas tecnologias regulatórias contratuais existentes. 0 País, com efeito, observou isso recentemente em complexas modelagens no setor aeroportuário e na tentativa de projeto do Trem de Alta Velocidade (TAV) pelo Governo Federal, o que demonstrou a relevância que se imprimiu à experiência dos atores privados estrangeiros naquele processo de contratação ${ }^{10}$.

Ilustra esta constatação, o magistério de Floriano Peixoto de Azevedo Marques Neto (2009, p. 79) a seguir transcrito:

[...] Assistimos na prática da Administração a mudanças relevantes. Há inegável aumento na complexidade das relações contratuais de que participa o Poder Público. A busca por soluções de financiamento das utilidades públicas (decorrência menos da crise fiscal, e mais da crescente demanda pelo provimento de direitos fundamentais) leva a uma busca de arranjos contratuais criativos e inovadores, o que pressiona por novas formas de relacionamento contratual.

Sem embargo, com arrimo no pensamento de Sabino Cassese, Fernando Dias Menezes de Almeida aponta que o problema do aumento da complexida-

9. Nessas modelagens, exigia-se uma experiência prévia no setor, além de uma joint venture com uma empresa estatal do setor, o que acarretou complexos arranjos societários nos consórcios a fim de que fossem atingidos os requisitos básicos do edital.

10. Aqui, uma das exigências editalícias era que o parceiro privado tivesse já operado um sistema de trem de alta velocidade, o que é, atualmente, inexistente no Brasil - exigindo-se, portanto, a participação de atores estrangeiros no processo, à semelhança do que ocorreu no setor aeroportuário. de do fenômeno contratual não consiste apenas na necessidade de inovar, com a busca de novas formas contratuais, mas também em verificar as gradações de intensidade com as quais a atividade contratual tem se manifestado na Administração Pública (ALMEIDA, 2012, p. 340).

E o que fora acima exposto acerca do track record, vale dizer, demonstra realmente que a Administração Pública, muito mais do que inovar na administração contratual, deseja apropriar experiências bem-sucedidas próprias, de outros entes federativos ou de outros países, adaptando-as à realidade específica atual. Essa seria, aliás, uma das facetas características da chamada nova Administração Pública e que pode ser verificada da seguinte forma: se no passado a experiência da Administração Pública era apropriada, principalmente, por meio de reformas normativas, hoje em dia esta mesma experiência exsurge, também, absorvida mediante todo o processo de execução dos contratos administrativos celebrados, e percebidos na esfera regulatória das infraestruturas e dos serviços públicos.

Outrossim, o sentido de apropriação ora aventado não se dá no tocante à eficiência adquirida pelo setor privado durante a execução do contrato, mas sim, no sentido de como os contratos administrativos servem de aprendizado ao Poder Público que, por sua vez, passa a adquirir uma expertise cada vez maior ao longo da execução contratual de cada atividade prestada pelo setor privado, permitindo futuramente que seus próximos contratos sejam celebrados com maior grau de sofisticação e de potencialidade de satisfação dos interesses públicos perseguidos.

Trata-se, pois, de uma preocupação que ultrapassa o ponto da transição - em termos de paradigmas teóricos - da negação para a aceitação de que a Administração possa se relacionar contratualmente no desempenho da função administrativa, e chega à questão que concerne à possibilidade da Administração dispor de arranjos contratuais testados e adequados 
para a satisfação dos interesses públicos (ALMEIDA, 2012, p. 376-377).

Neste passo, vale ainda destacar a locução “administração contratual”, anteriormente mencionada, verificando sua sintonia com o entendimento expresso nas palavras de Gaspar Ariño Ortiz, quando assinala que

[...] assim, fala-se de uma das características mais importantes do Estado atual: sua condição de Estado Contratual, apontando a utilização pelo Estado de organizações privadas, com ou sem fins lucrativos, para alcançar os seus fins públicos. (ARIÑO ORTIZ, 1999, p. 26. Grifos nossos)

\section{NOVA CONTRATUALIDADE ADMINISTRATIVA: OS CONTRATOS DE PARCERIAS COMO MANIFESTACÕES CARACTERÍSTICAS DA ADMINISTRAÇÃO CONTRATUAL}

O tópico anterior partiu da premissa de que o Estado Pós-Moderno é necessariamente um Estado Pluriclasse e que, por isso, possui interesses públicos pluralizados $^{11}$, por vezes colidentes diante das situações concretas, razão pela qual o Poder Público coloca-se na posição de árbitro diante destes inevitáveis conflitos ${ }^{12}$.

Pelo caminho até aqui trilhado, destacou-se a expressão “Administração contratual”. Outras, tais como "Estado contratual”, “Estado negociador", “Estado contratante" e etc., também são nomenclaturas utilizadas para designar a mediação estatal dos interesses públicos conflitivos mediante o uso de técnicas negociais que abrem margem à participação do particular

\footnotetext{
11. Consoante posição adotada e solidamente justificada por Floriano Peixoto de Azevedo Marques Neto em seu já mencionado - vide nota de rodapé $\mathrm{n}^{\circ}$ 8 retro - "Regulação estatal e interesses públicos". (MARQUES NETO, 2002). 12. Já que os conflitos tendem a ocorrer seguindo a proporção do crescimento da complexidade das demandas sociais e das consequentes postulações de seus respectivos grupos de pessoas - fenômeno que pode ser chamado de fragmentação social - perante as autoridades estatais.
}

nos procedimentos de negociação, e que evidenciam propriamente a existência de um novo fenômeno contratual, conforme, também, já evidenciado no tópico anterior, na administração pública.

Destarte, isso é bem sintetizado por Odete Medauar (2009, p. 151), quando em uma de suas passagens, explica que:

\begin{abstract}
O clima de aproximação entre Estado e sociedade foi se acentuando no curso das últimas décadas, a ponto de surgir a denominação Estado reflexivo. Da ouvida de indivíduos, isolados ou em grupo, emergiram as práticas de negociação, acordo, busca de consenso, mediação de conflitos, ponderação de vários interesses existentes numa situação. Alguns nomes dados ao Estado expressam tais práticas: Estado negociador, Estado mediador, Estado incentivador, Estado cooperativo. Os vínculos mais estreitos entre público e privado, a atuação menos imperial da Administração, as práticas de negociação e a busca de consenso propiciaram intenso uso de técnicas contratuais na ação administrativa, daí também qualificar-se o estado como Estado contratante ${ }^{13}$.
\end{abstract}

Nota-se que esta linha de Estado Negociador exsurge representada por conceitos que estão sendo paulatinamente desenvolvidos na Administração Pública brasileira. Um bom destaque neste sentido pode ser extraído dos chamados Procedimentos de Manifestação de Interesse (PMIs), bem como das Manifestações de Interesse da Iniciativa Privada (MIPs) ${ }^{14}$,

13. Sem embargo, a autora ainda traz a citação de Jean-Pierre Gaudin (1999. P. 10): "preconiza-se uma nova ação pública, debatida e negociada, menos longe dos cidadãos. Negociação, parceria e mediação são, assim, palavras estreitamente associadas pelos autores de um número crescente de políticas públicas" (Tradução livre).

14. "Com a multiplicidade de regulamentações, originou-se o que se convencionou a chamar de Manifestação de Interesse da Iniciativa Privada - MIP e Procedimento de Manifestação de Interesse - PMI. O primeiro visa a descrever uma atividade proativa da sociedade, na qual eventuais interessados em que um projeto de infraestrutura seja analisado e efetivamente concretizado pelo ente federativo apresentam uma ideia "do zero", de forma inaugural: seria como apresentar um projeto para uma ponte entre duas margens, nunca antes concebida pelo setor público. Já no caso dos PMIs, é a Administração Pública que "planta a semente" para que interessados possam apresentar projetos: seria como o poder público dizer que quer receber projetos de uma ponte entre essas duas margens, mas não especifica onde, como e nem com qual material ela será construída. Ademais, cumpre ressaltar que o surgimento da Lei das PPPs também fez com que alguns entes federativos regulamentassem essa hipótese apenas para os casos de PPPs (as "con- 
além de técnicas - ainda iniciais - de diálogo competitivo vislumbradas pelo Regime Diferenciado de Contratações $(\mathrm{RDC})^{15}$.

Prosseguindo, nota-se, também, que inerente ao conceito de administração contratual é - e parece mesmo óbvio que assim seja - a ideia de se governar por contrato. Esta afirmação não despreza a importância do papel desempenhado pelo ato administrativo dentro do contexto de atividade administrativa como um todo. Contudo, realça de acordo com tudo o que já fora explicado, o fato do crescimento de situações em que o advento de novos arranjos contratuais proporciona, pelo menos em tese, uma gama de soluções mais eficientes para a satisfação dos mais diversos interesses públicos que perfazem uma sociedade pluriclasse ${ }^{16}$.

Governar por contrato, com efeito, no exato sentido colocado por Jean-Pierre Gaudin (MEDAUAR, 2009, p. 151), ou seja, atenuando as situações de verticalida$\mathrm{de}^{17}$ nas relações contratuais entre o Poder Público e o particular, significa conceber, através da expressão (nova) contratualidade administrativa ${ }^{18}$, que, conforme a dicção de Massimo Severo Giannini (1980, p. 83-84) ${ }^{19}$,

cessões patrocinadas" ou "concessões administrativas"), e não para o caso das "concessões comuns" (as que ocorrem por conta e risco do investidor)" (CARVALHO, 2012)

15. Vide o artigo 26 da Lei n 12.462, de 2011, a qual instituiu o RDC: “Art. 26. Definido o resultado do julgamento, a administração pública poderá negociar condições mais vantajosas com o primeiro colocado. Parágrafo único. A negociação poderá ser feita com os demais licitantes, segundo a ordem de classificação inicialmente estabelecida, quando o preço do primeiro colocado, mesmo após a negociação, for desclassificado por sua proposta permanecer acima do orçamento estimado."

16. Nas palavras de Fernando Dias Menezes de Almeida, "[...] a maior complexidade das possibilidades de relação da Administração com parceiros privados evidencia que não necessariamente a via unilateral é a melhor para se garantir a consecução da função administrativa" (ALMEIDA, 2012, p. 377).

17. O termo "verticalidade" é aqui entendido nos termos postos por Celso Antônio Bandeira de Mello: "A posição de supremacia, extremamente importante, é muitas vezes metaforicamente expressada através da afirmação de que vigora a verticalidade nas relações entre Administração e particulares; ao contrário da horizontalidade, típica das relações entre estes últimos" (BANDEIRA DE MELLO, 2011, p. 70).

18. Para aprofundamento do que é pertinente às novas configurações da "contratualidade administrativa", ver os artigos "Do contrato administrativo à administração contratual” (MARQUES NETO, 2009, p. 74-81), "O futuro das cláusulas exorbitantes nos contratos administrativos" (MOREIRA NETO, 2008, p. 571-592) e a obra "Contrato Administrativo" (ALMEIDA, 2012). 19. Tradução livre. o direito que regula a atividade das administrações públicas tende, portanto, a compor-se de uma parte fortemente autoritária - direito administrativo em sentido estrito - e, de outra, em que se tem como válida, ainda que com certas adaptações, a normativa privada.

O trecho supracitado aponta, obviamente, para uma tendência evolutiva no exercício da atividade administrativa, tendência esta marcada pela “[...] evolução de um modelo centrado no ato administrativo (unilateralidade) para um modelo que passa a contemplar acordos administrativos (bilateralidade e multilateralidade)" (OLIVEIRA; SCHWANKA, 2010, p. 229) ${ }^{20}$ e consequentemente incrementa as possibilidades contratuais para a instrumentalização de parcerias entre o Estado e o particular.

Nada obstante, as Parcerias Público-Privadas corroboram justamente para referida multilateralidade, de acordo com o que tem sido constantemente testado nos modelos de competições por projetos trazidos junto às modelagens de PMIs, nos quais diversos particulares dialogam com a administração pública a fim de demonstrar uma determinada visão que melhor se coadune aos interesses públicos ${ }^{21}$. Assim, é interessante observar como Gustavo Justino de Oliveira posiciona as parcerias entre o público e o privado dentro da nova contratualidade administrativa mencionada por Giannini:

As PPP encaixam-se nessa nova fase de contratualização administrativa ou simplesmente nova contratualização administrativa (ainda em evolução), em que:

a) Privilegia-se sobremaneira a cultura do diálogo entre o parceiro público e privado;

b) Confere-se maior atenção às negociações prelimi-

20. Sem prejuízo, acrescenta-se que este novo modelo, pautado pela bilateralidade e multilateralidade, naturalmente prestigia a comunicação entre Administração e administrado, no sentido explanado por Thiago Marrara: “[...] A comunicação entre Administração e administrado é o que permite cooperação, coordenação, transparência e democratização decisória, ampliando as chances de aceitabilidade das medidas tomadas pelo administrador público e, por conseguinte, a obediência social”. (MARRARA, 2012, p. 281). 21. $O$ caso do PMI da Linha 18 do Metrô de São Paulo é salutar nesse sentido, o qual, sendo originalmente um PMI para coletar subsídios ao Estado, originou posteriormente uma PPP a partir das contribuições trazidas por dois grupos empresariais na área de infraestrutura de transportes. 
nares ao ajuste que devem ser transparentes);

c) Abrem-se espaços para trocas e concessões mútuas entre os parceiros, visando um balanceamento dos interesses envolvidos;

d) Diminui-se a imposição unilateral de cláusulas por parte da Administração, com o proporcional aumento da interação entre os parceiros para o delineamento e fixação das cláusulas que integrarão o contrato; e) Institui-se uma maior interdependência entre as prestações correspondentes ao parceiro público e ao parceiro privado, inclusive com a atribuição de garantias a esse último, tidas como não usuais nos contratos tradicionais firmados pela Administração. (OLIVEIRA, 2010, p. 93-94)

Tal consolidação - a da nova contratualidade administrativa como tendência evolutiva e marca registrada da chamada administração contratual também pode ser abordada por outra perspectiva, posta a qualificá-la como matriz ideológica pela qual o Estado Moderno transformou-se em Estado Pós-Moderno. Este pensamento é proposital para a aproximação da perspicaz percepção de Maria Sylvia Zanella Di Pietro (2008, p. 1-2):

O Direito Administrativo vem sofrendo paulatinas alterações no decurso do tempo. Ou poderíamos dizer que todo o Direito vem sofrendo alterações como decorrência da própria mudança na forma de conceber-se o Estado.

Fala-se, em toda parte, em reforma do Estado, em reforma da Constituição, em reforma da Administração Pública.

[...]

0 que muda na realidade?

Parece que o que muda é principalmente a ideologia, é a forma de conceber o Estado e a Administração Pública. Não se quer mais o Estado prestador de serviços; quer-se o Estado que estimula, que ajuda, que subsidia a iniciativa privada; quer-se a democratização da Administração Pública pela participação dos cidadãos nos órgãos de deliberação e consulta e pela colaboração entre o público e privado na realização das atividades administrativas do Estado; quer-se a diminuição do tamanho do Estado para que a atuação do particular ganhe espaço; quer-se a flexibilização dos rígidos modos de atuação da Administração Pública, para permitir maior eficiência; quer-se a parceria entre público e privado para substituir-se a Administração Pública dos atos unilaterais, a Administração Pública autoritária, verticalizada, hierarquizada.
Da lição ora colacionada, depreende-se, por parte da autora, o uso dos termos "colaboração entre o público e privado na realização das atividades administrativas do Estado" e "parceria entre público-privado para substituir-se a Administração Pública dos atos unilaterais". Os contratos de parceria público-privada constituem verdadeiros mecanismos instrumentais da nova contratualidade administrativa, sobretudo se considerados como parte do recente programa de reforma do Estado no Brasil, iniciado na década de $1990^{22}$, porquanto alocados dentro dos campos de manifestações da administração contratual.

Embora não se negue o caráter adesivo ainda bastante forte dos contratos administrativos - e isso não pode ser perdido de vista, já que as parcerias entre público-privado não existem sem esta instrumentalização jurídica -, é de se notar uma dependência cada vez maior do Estado não só em relação aos recursos provenientes do parceiro privado, como também em relação à expertise que muitas vezes ele apresenta na prestação de determinados serviços públicos (MODESTO, 2005, p. 29).

Para aproximar, dogmaticamente, a ideia de atuação do Estado à noção de manifestações da administração contratual, em termos mais específicos e mediante brevíssima síntese da classificação elaborada por Floriano Peixoto de Azevedo Marques Neto (2009), pode-se dizer que a administração contratual manifesta-se dentro de diferentes áreas, basicamente resumida pela a atividade de polícia por: campo dos serviços públicos, função de fomento, atividade de regulação e função de intervenção na economia.

De seu turno, com diferente abordagem terminológica, mas não fora do debatido aumento de complexidade do fenômeno contratual da Administração Pública, Fernando Dias Menezes de Almeida (2012,

22. E cujo ápice deu-se, como lembra Carlos Ari Sundfeld, a partir de 1994, com as medidas de privatização das grandes empresas federais, de flexibilização de monopólios de alguns serviços públicos, de estímulo ao Terceiro Setor e etc., tomadas pelo Governo Fernando Henrique Cardoso (1994-2002), bem como pela edição, acontecida durante o Governo Lula (2003-2010), da Lei $n^{\circ} .11079 / 04$, a chamada leis das PPPs. (SUNDFELD, 2007, p. 15-44). 
p. 236-316) propõe uma detalhada sistematização da matéria, dividindo em módulos convencionais necessários para a criação de situação jurídica, o que aqui tem sido tratado - conforme se depreende do acima entabulado, bem como do título do tópico presente - como tipos de manifestações da administração contratual. Nesta esteira, o seu estudo agrupa os principais tipos de módulos convencionais em quatro categorias, a saber: "módulos convencionais de cooperação, módulos convencionais de concessão, módulos convencionais instrumentais - esses três configurando hipóteses em que a convenção é indispensável para a criação de situação jurídica - e módulos convencionais substitutivos de decisão unilateral da Administração" (ALMEIDA, 2012, p. 356).

Sobre em quais campos e com qual intensidade os contratos de parceria entre público e privado se manifestam, isso irá depender da acepção utilizada para conceituar esta manifestação da administração contratual. A rigor, quando se utiliza o termo parceria de forma isolada, isto é, sem o complemento público-privada, o entendimento recai sobre uma acepção ampla ou até “amplíssima”23 do termo, de modo a permitir que os referidos contratos sejam localizados em praticamente todos os campos acima mencionados.

\section{OS CONTRATOS DE PARCERIA COMO INSTRUMENTOS PARA A REALIZAÇÃO DOS INTERESSES PÚBLICOS}

Por opção metodológica, a delimitação conceitual, ora utilizada para definir contratos de parcerias, é a mesma proposta apresentada por Floriano Peixoto de

23. "Há várias formas de se entender "parceria público-privada". De uma maneira geral, sempre que o Poder Público se socorre de um ente privado, fora da relação de compra de força de trabalho (primado da relação laboral submetida ao direito público), temos uma espécie de parceria. Nesta acepção ampla - diria eu, amplíssima - estariam compreendidas todas as formas de vínculo obrigacional entre os entes públicos e pessoas privadas, envolvendo desde convênios até os instrumentos de delegação da prestação de serviços públicos (por concessão ou permissão)". (MARQUES NETO, 2005, p. 280)
Azevedo Marques Neto (2005, p. 287-288) para conceituar as parcerias público-privadas (PPPs):

[...] PPP é o ajuste firmado entre Administração Pública e iniciativa privada, tendo por objeto a implantação e a oferta de empreendimento destinado à fruição direta ou indireta da coletividade, incumbindo-se à iniciativa privada da sua concepção, estruturação, financiamento, execução, conservação e operação, durante todo o prazo para ela estipulado, e cumprindo ao Poder Público assegurar as condições de exploração e remuneração pela parceria privada, nos termos do que for ajustado, e respeitada a parcela de risco assumida por uma e outra das partes.

Referida opção justifica-se - para os fins do presente trabalho - porque nela podem ser enquadradas diversas formas de parcerias, excluindo a necessidade de manter-se preso aos ditames da Lei 11.079/200424.

Posta a demonstração - construída por uma linha de pensamento exposta pelos argumentos delineados na sequência dos tópicos anteriores - de que os contratos de parceria são verdadeiros instrumentos da nova contratualidade administrativa, dado o seu enquadramento na categoria de típica manifestação da administração contratual, cumpre, nesse momento, tratar desta própria aptidão instrumental para a consecução dos interesses públicos presentes na sociedade.

Aludida aptidão é percebida, em verdade, por mero desdobramento lógico do raciocínio até aqui entabulado, a partir da formulação de uma tela de análise das noções de interesses públicos e administração contratual, preservando o entendimento de

\footnotetext{
24. "Nesta definição cabem infinitas hipóteses de parceria. Nela estariam compreendidas hipóteses de delegação de serviços econômicos (via concessão, com tarifa e receitas complementares; ou via permissão, com receitas alternativas); o cometimento de atividades que não caracterizam serviços públicos econômicos; a delegação de serviços públicos indivisíveis; a concessão de bem ou de obra pública sem delegação do serviço (mas com incumbência de operação da infra-estrutura concedida); o cometimento do ônus de recuperação e manutenção de um bem público, sem cobrança do usuário, mas com possibilidades de receitas ancilares; a construção de prédios públicos para posterior arrendamento à Administração Pública; a execução de empreendimentos habitacionais para aquisição por população de baixa renda - entre outras modalidades que certamente surgiriam no devir da implantação do instituto". (MARQUES NETO, 2005, p. 288).
} 
que a nova contratualidade administrativa é, ao mesmo tempo, tendência evolutiva da atuação estatal e marca característica da referida administração contratual, que aproxima Estado e sociedade, colocando-os numa relação dialógica própria do contexto do Estado Pós-Moderno e que quebra os paradigmas da Modernidade, deixando claro que o Poder Público não pode ser mais considerado como responsável exclusivo pela realização dos interesses públicos ${ }^{25}$; 0 que redunda na irrefutável constatação da necessidade de pactos, ou seja, de instrumentos de pactuação entre as esferas pública e privada, quando elas se ajustam para a busca da satisfação das demandas da coletividade - função instrumental desempenhada dentro deste quadro, por óbvio, pelos chamados contratos de parcerias $^{26}$.

Em paralelo, contudo, por uma abordagem restrita aos contratos de parceria público-privada, disciplinados pela Lei 11.079/04, não é demais destacar as ideias apresentadas por Gustavo Justino de Oliveira, para quem o Estado Brasileiro, mesmo na hipótese de não dispor de recursos públicos suficientes, não pode eximir-se da obrigação constitucional de garantir o desenvolvimento nacional ${ }^{27}$ (decorrência direta do art. $3^{\circ}$, inciso $\mathrm{II}$, e art. $5^{\circ}$, $\S 2^{\circ}$, ambos da

25. Falando sobre "O mito da exclusividade estatal na consecução do interesse público", Floriano Peixoto de Azevedo Marques Neto aduz: "O mito se contradiz diariamente pelos fatos. Não é só na esfera pública que ocorre a consagração dos interesses da coletividade. Ninguém duvida que fornecer alimentos para as populações seja de interesse público. E em nossas sociedades ocidentais, exceto raríssimas e discutíveis exceções, os encarregados desta função são os agentes econômicos privados: produtores de alimentos, distribuidores, comerciantes, etc. Tampouco se discute que a educação seja uma necessidade de interesse coletivo. Na grande maioria dos países a educação é provida pela combinação das ações estatais e de outras entidades, empresariais, religiosas ou beneméritas. 0 mesmo podemos dizer nos campos da assistência social, da saúde, do transporte ou da comunicação e da imprensa [...]". (MARQUES NETO, 2011, p. 1087. Tradução livre).

26. Em sentido semelhante, novamente, Floriano Peixoto de Azevedo Marques Neto: "[...] A busca dos interesses gerais (mesmo a tutela das hipossuficiências), hodiernamente há de se dar conjugando as ações privadas e públicas. Em algumas oportunidades com o Estado regulando proativamente (não meramente mediante regulação econômica coibidora das falhas de mercado) a atuação dos agentes privados; em outras induzindo e fomentando esses agentes. Neste segundo plano, assume forte importância o mecanismo de parcerias" (MARQUES NETO, 2008, p. 57. Grifos nossos).

27. "Considerando o processo evolutivo dos direitos fundamentais, o direito ao desenvolvimento insere-se no segmento dos denominados direitos fundamentais de terceira dimensão" (OLIVEIRA, 2005, p. 97).
CF), que, por extensão, acaba por promover o fundamento republicano da dignidade da pessoa humana (decorrência direta do art. $1^{\circ}$, inciso III, da CF) (OLIVEIRA, 2005, p. 93-1000).

Por conseguinte, defende esse autor que, diferentemente do que acontece com os contratos regrados pelas Leis 8.666/93 e 8.987/95, os contratos de PPP possuem regime jurídico específico, o que faz atenuar a presença abundante das denominadas cláusulas exorbitante nas relações contratuais dessa natureza, ampliando as "[...] bases de negociação das cláusulas contratuais que irão estabelecer a regulamentação dos interesses parceiros, sem o enfraquecimento da (imanente) bilateralidade desse negócio jurídico" (OLIVEIRA, 2005, p. 112) e "sinalizando um maior equilíbrio nas posições assumidas por ambas as partes” (OLIVEIRA, 2005, p. 114).

Logicamente, os aspectos acima mencionados constituiriam vantagens suficientes para - de acordo com o seu pensar - legitimar a categoria de contratos que por ela estejam regidos à condição de instrumento mais adequado para a consecução dos interesses públicos, sobretudo por estarem inseridos em um “[...] cenário de escassez de recursos orçamentários para a execução de projetos de altos custos, em que existe um grave déficit de projetos estruturantes em áreas como transportes, saneamento básico e saúde" (OLIVEIRA, 2005, p. 111). Infere-se daí, portanto, a importância impressa ao tema da nova contratualidade administrativa, como um dos mais instigantes tópicos de análise doutrinária da última década.

E ainda nessa linha de maior diálogo e multilateralidade, conforme até aqui explorado, é de se esperar que referidas condutas colaborativas (no presente ensaio foram explorados os exemplos dos PMIs e MIPS) tendam a bem designar os principais instrumentos contratuais da Administração Pública, restando como desafio futuro, efetivamente, a grande questão da chamada paridade informacional. Difícil, pois, cumpre dizer, é evitar que esse diálogo não seja permea- 
do por assimetrias de informações, de tal sorte que o setor público não venha a sofrer com a contingência de maiores óbices na captura dos interesses públicos adjacentes a esse diálogo com os parceiros privados.

\section{RESUMO DA LINHA DE RACIOCÍNIO PROPOSTA E BALANÇO DOUTRINÁRIO}

As ideias enunciadas ao longo do presente trabalho podem ser condensadas pela linha de raciocínio exposta no tópico anterior, repise-se, basicamente, a partir da formulação de uma tela de análise das noções de interesses públicos e administração contratual.

Por essa linha, impossível tratar do conceito de administração contratual isolando-o da tendência evolutiva de atividade administrativa que o caracteriza, a chamada nova contratualidade administrativa.

Institutos novos, notadamente os da PMIs e o das MIPs, também, foram abordados nos sentido de demonstrar como a administração pública contemporânea vem observando outros valores e conceitos na relação jurídico-administrativa (cooperação, consensualidade, diálogo competitivo) em conjunção ao que já se observava tradicionalmente, no decorrer da história (formalismo, ato administrativo, interesse público etc.).

Ainda, pela mesma linha e conforme todo o até aqui demonstrado, entende-se que essa tendência evolutiva aproxima Estado e sociedade e os coloca dentro de uma relação dialógica inerente ao contexto do Estado Pós-Moderno, deixando claro que o Poder Público não pode ser mais tido como responsável exclusivo pela consecução dos interesses públicos. Tal fato impõe constatar a necessidade de pactos, isto é, de instrumentos de pactuação entre as esferas pública e privada para a busca da satisfação das demandas da coletividade - função instrumental desempenhada dentro desse quadro, obviamente, pelos chamados contratos de parceria.
Já em síntese conceitual, verifica-se que os contratos de parcerias apresentam-se como manifestações características do modelo de administração contratual, porque instrumentalizam todas as situações jurídicas referentes à nova contratualidade administrativa.

Sob o ponto de vista restrito às parcerias regulamentadas pela Lei 11.079/2004 - os chamados contratos de PPP -, parece assente que referidos contratos, conquanto disciplinados por um regime jurídico específico, constituem instrumentos potencialmente mais viáveis para a consecução de interesses públicos entranhados num cenário de infraestrutura deficien$t^{28}$, sobretudo nos setores de saneamento, aeroportos e rodovias (WERNECK DE OLIVEIRA, 2005, p. 44.); e que revela, conforme adverte Adílson Abreu Dallari (2005, p. 365): “[...] dois pontos fundamentais: a absoluta necessidade de uma atuação eficaz e urgente para a solução de problemas que não comportam adiamento e a impossibilidade de solução pelos meios tradicionalmente utilizados”. A junção destes dois fatores provoca a Administração Pública a tomar "[...] providências imediatas e, ao mesmo tempo" com "o desembolso de recursos públicos apenas no futuro" (DALLARI, 2005, p. 365). Por isso "[...] As PPPs podem ser uma forma de solução para tais problemas" (DALLARI, 2005, p. 365.).

Em contrabalanço, contudo, e apenas a título ilustrativo, destaca-se uma importante advertência, por parte da doutrina, em relação ao futuro dos contratos de PPP (Lei 11.079/2004), cabendo como alerta o apelo a algumas citações doutrinárias, como ao próprio Adílson Abreu Dallari (2005, p. 366): "Não se pode, entretanto, entender as PPPs como uma solução mágica, totalmente segura e isenta de dificuldades e até mesmo de contradições"; corroborado pelo discurso de Gustavo Justino de Oliveira (2005, p. 119): "No entanto, importa esclarecer que a PPP não é uma

28. "Um dos principais problemas que se enfrentam hoje no Brasil é a infra-estrutura deficiente. Não existem condições - eis um dos poucos consensos entre os economistas - de crescer sustentadamente sem investimentos em infra-estrutura. Para destravar o potencial de crescimento da atividade econômica, é muito importante evitar os gargalos de infra-estrutura que o país enfrenta hoje”. (PINTO, 2005, p. 28-29). 
poção milagrosa para a viabilização do crescimento econômico e a promoção do desenvolvimento, nem um antídoto infalível à estagnação social que assola o país”; bem como pela preocupação - para desfecho de Dinorá Adelaide Musetti Grotti (2005, p. 231): “Não nutramos, porém, ilusões quanto a ser a PPP verdadeira panaceia, a legitimar, por sua só existência, a solução para todos os problemas nacionais".

Tais advertências, não obstante possam parecer genéricas, guardam a importância da preocupação de se conter um otimismo possivelmente exacerbado na tentativa de sistematizar novas - e mais eficientes - formas de solução para os problemas sociais que demandam uma atuação do Estado, cumprindo justamente o seu papel doutrinário, isto é, propositivo e inovador na formulação das diretrizes de atuação daqueles que são operadores do Direito ou administradores da coisa pública (MARRARA, 2010, p. 256.).

\section{CONSIDERAÇÕES FINAIS}

Em consonância com o inicialmente proposto, o objetivo de distinguir as expressões administração contratual, nova contratualidade administrativa e contratos de parcerias, a fim de que sejam estabelecidos parâmetros conceituais adequados para cada um destes conceitos, resulta pela linha de raciocínio até aqui exposta, nas derradeiras considerações abaixo delineadas.

Primeiramente, é de se constatar que a leitura da expressão "contratos de parcerias" demanda relativa matização conceitual, eis que, a rigor, a utilização do termo "parcerias", feita de forma isolada, corresponde a uma acepção ampla deste instituto, ao passo que o uso do complemento público-privada, ou até mesmo de sua costumeira abreviação - PPP -, segue associada às concessões especificamente regradas pela Lei 11.079/2004. Por esta acepção ampla, o conceito de contratos de parce- rias compreende, basicamente, "todas as formas de vínculo obrigacional entre os entes públicos e pessoas privadas, envolvendo desde convênios até os instrumentos de delegação da prestação de serviços públicos (por concessão ou permissão)" (MARQUES NETO, 2005, p. 280).

Ademais, uma das principais simbologias desses contratos de parcerias é o fato de, atualmente, o próprio particular estar contribuindo com a administração pública na construção da relação jurídico-administrativa, notadamente mediante os PMIs e MIPs, já que as diversas formas de vínculo obrigacional existentes entre os entes públicos e pessoas privadas constituem, em verdade, frutos de uma tendência evolutiva marcada pelo aumento da complexidade do fenômeno contratual na Administração Pública. A essa tendência, que de certa maneira, também, é marca da passagem do Estado Moderno para o Estado Pós-Moderno, dá-se o nome de nova contratualidade administrativa.

E, por fim, entende-se por administração contratual o conceito que define o modelo de administração pública que evidentemente age em resposta ao aumento da complexidade de seu fenômeno contratual e, por isso, resulta da nova contratualidade administrativa, sendo pautado pela mediação estatal dos interesses públicos conflitivos por meio do uso, cada vez maior e constante, de técnicas negociais instrumentalizadas pelos contratos de parcerias, segundo a proposta conceitual defendida neste trabalho.

\section{REFERÊNCIAS}

ALMEIDA, Fernando Dias Menezes de. Contrato administrativo. São Paulo: Quartier Latin, 2012.

ANTUNES, Luís Filipe Colaço. A tutela dos interesses difusos em direito administrativo. Coimbra: $\mathrm{Al}$ medina, 1989. 
ARIÑO ORTIZ, Gaspar. El retorno a lo privado: ante uma nueva encrucijada histórica. In (org.) Privatización y liberalización de servicios. Madrid: Universidad Autónoma de Madrid, 1999.

BANDEIRA DE MELLO, Celso Antônio. Curso de direito administrativo. São Paulo: Malheiros, 2011.

BINENBOJM, Gustavo. Uma teoria de direito administrativo: direitos fundamentais, democracia e constitucionalização. Rio de Janeiro: Renovar, 2006.

CARVALHO, André Castro. As MIPs e os PMIs e sua situação atual no direito brasileiro. Informativo Direito Público e Cultura Jurídica, n.66. sbdp. 23 out. 2013. Disponível em: <http://www.sbdp.org.br/artigos_ver. php?idConteudo=97>. Acesso em: 18 jun. 2014.

DALLARI, Adílson Abreu. Parcerias em transporte público. In SUNDFELD, Carlos Ari (coord.). Parcerias público-privadas. São Paulo: Malheiros, 2005.

DALLARI, Dalmo de Abreu. Interesse público na contratação das entidades da administração descentralizada. Cadernos Fundap. São Paulo, ano 5, n.16, jul./set. 1985.

DI PIETRO, Maria Sylvia Zanella. Discricionariedade administrativa na Constituição de 1988. São Paulo: Atlas, 2007.

DI PIETRO, Maria Sylvia Zanella. Parcerias na administração pública: concessão, permissão, franquia, terceirização, parceria público-privada e outras formas. São Paulo: Atlas, 2008.

GAUDIN, Jean-Pierre. Gouverner par contrat: l'action publique em question. Paris: Presses de Siences Politiques, 1999.

GIANNINI, Massimo Severo. Premissas sociológicas e históricas del derecho administrativo. Madrid: Instituto Nacional de Administración Pública, 1980.
GROTTI, Dinorá Adelaide Musetti. A experiência brasileira nas concessões de serviço público. In. SUNDFELD, Carlos Ari (coord.). Parcerias público-privadas. São Paulo: Malheiros, 2005.

MARQUES NETO, Floriano Peixoto de Azevedo. As parcerias público-privadas no saneamento ambiental. In SUNDFELD, Carlos Ari (coord.). Parcerias público-privadas. São Paulo: Malheiros, 2005.

MARQUES NETO, Floriano Peixoto de Azevedo. Discricionariedade administrativa e controle judicial da administração. Processo civil e interesse público, organizado por Carlos Alberto de Salles. São Paulo: RT, 2003.

MARQUES NETO, Floriano Peixoto de Azevedo. Do contrato administrativo à administração contratual. Revista do Advogado, n.107. São Paulo: Associação dos Advogados de São Paulo, 2009.

MARQUES NETO, Floriano Peixoto de Azevedo. La moderna regulación: La búsqueda de un equilibrio entre lo público y lo privado. In: Juan Miguel de la Cuétera Martinez; José Luis Martinéz López-Muniz; Francisco J. Villar Rojas. (Org.). Derecho administrativo y regulación económica - liber amicorum Gaspar Ariño Ortiz. Madrid: La Ley, 2011.

MARQUES NETO, Floriano Peixoto de Azevedo. Reajuste e revisão nas parcerias público-privadas. In SOUZA, Mariana Campos de. (coord.). Parceria público-privada: aspectos jurídicos interessantes. São Paulo: Quartier Latin, 2008.

MARQUES NETO, Floriano Peixoto de Azevedo. Regulação estatal e interesses públicos. São Paulo: Malheiros, 2002.

MARRARA, Thiago. O princípio da publicidade: uma proposta de renovação. In MARRARA, Thiago (org.). Princípios de direito administrativo: legalidade, segurança jurídica, impessoalidade, publicidade, motivação, eficiência, moralidade, razoabilidade e interesse público. São Paulo: Atlas, 2012. 
MARQUES NETO, Floriano Peixoto de Azevedo. As fontes do Direito Administrativo e o Princípio da Legalidade. In DI PIETRO, Maria Sylvia Zanella; RIBEIRO, Carlos Vinícius Alves. (coord.). Supremacia do interesse público e outros temas relevantes do direito administrativo. São Paulo: Atlas, 2010.

\section{MEDAUAR, Odete. 0 direito administrativo em evo-} lução. São Paulo: RT, 1992.

MEDAUAR, Odete. O florescimento de novas figuras contratuais. Revista do Advogado, n.107. São Paulo: Associação dos Advogados de São Paulo, 2009.

MODESTO, Paulo. Reforma do Estado, formas de prestação de serviços ao público e parcerias público-privadas: demarcando as fronteiras dos conceitos de serviço público, serviços de relevância pública e serviços de exploração econômica para as parcerias público-privadas. Revista Eletrônica de Direito Administrativo Econômico. Salvador: Instituto de Direito Público da Bahia, $n^{\circ} 2$, 2005. Disponível em: <http:www.direitodoestado.com.br>. Acesso em: 12 jan. 2013.

MOREIRA NETO, Diogo de Figueiredo. O futuro das cláusulas exorbitantes nos contratos administrativos. In ARAGÃO, Alexandre Santos; MARQUES NETO, Floriano Peixoto de Azevedo (org.). Direito administrativo e seus novos paradigmas. Belo Horizonte: Fórum, 2008.

MOREIRA NETO, Diogo de Figueiredo. Quatro paradigmas do direito administrativo pós-moderno: legitimidade - finalidade - eficiência - resultados. Belo Horizonte: Fórum, 2008.

OLIVEIRA, Gustavo Justino de. A arbitragem e as parcerias público-privadas. In SUNDFELD, Carlos Ari (coord.). Parcerias público-privadas. São Paulo: Malheiros, 2005.
OLIVEIRA, Gustavo Justino de. Estado contratual, direito ao desenvolvimento e parceria público-privada. In JUSTEN, Monica Spezia; TALAMINI, Eduardo (coord.). Parcerias público-privadas: um enfoque multidisciplinar. São Paulo: Revista dos Tribunais, 2005.

OLIVEIRA, Gustavo Justino de. A arbitragem e as parcerias público-privadas. Direito administrativo democrático. Belo Horizonte: Fórum, 2010.

OLIVEIRA, Gustavo Justino de. SCHWANKA, Cristiane. A administração consensual como a nova face da administração pública no século XXI: fundamentos dogmáticos, formas de expressão e instrumentos de ação. Direito administrativo democrático. Belo Horizonte: Fórum, 2010.

OLIVEIRA, Luiz Henrique Werneck de. Parcerias público-privadas: visões antagônicas, conflitos complexos, oportunidades pendentes. In JUSTEN, Monica Spezia; TALAMINI, Eduardo (coord.). Parcerias público-privadas: um enfoque multidisciplinar. São Paulo: Revista dos Tribunais, 2005.

PINTO, Marcos Barbosa. Parcerias público-privadas: panorama da nova disciplina legislativa. In JUSTEN, Monica Spezia; TALAMINI, Eduardo (coord.). Parcerias público-privadas: um enfoque multidisciplinar. São Paulo: Revista dos Tribunais, 2005.

PIZZORUSSO, Alessandro. Interesse pubblico e interessi pubblici. Revista Trismetrale di Diritto e Procedura Civile. Março de 1972.

SUNDFELD, Carlos Ari. Guia jurídico das parcerias público-privadas. In SUNDFELD, Carlos Ari (coord.). Parcerias público-privadas. São Paulo: Malheiros, 2007. 
1. Bacharel em Direito pela Faculdade de Direito de São Bernardo do Campo e Mestre em Direito do Estado pela Universidade de São Paulo. Advogado e Diretor Técnico I no Departamento Estadual de Trânsito de São Paulo. Email: murilo_ferro@ig.com.br 